\title{
The Effect of Vitamin C on the Rapid Induction of Aortic Changes in Rabbits
}

\author{
D. Sadava, D.Watumull, K. Sanders, and K. Downey \\ Joint Science Department, The Claremont Colleges, \\ Claremont, California 91711, USA
}

(Received September 5, 1981)

\begin{abstract}
Summary Male rabbits were injected intraperitoneally for five consecutive days with one of the following: (A) $0.3 \mathrm{ml} / \mathrm{kg}$ dimethyl ethylene glycol (solvent); (B) $40 \mathrm{mg} / \mathrm{kg}$ cholesterol and $8 \mathrm{mg} / \mathrm{kg}$ ergocalciferol in solvent; (C) same regimen as B with the addition of $150 \mathrm{mg} / \mathrm{kg}$ ascorbic acid in water. Daily blood samples were taken for determination of cholesterol and triglycerides, and for lipoprotein electrophoresis. After 5 days of injections, histological sections were made of the aorta at the arch. After 5 days, group B, as compared with group A, had higher serum cholesterol $(150 \mathrm{mg} / \mathrm{dl} v s .50 \mathrm{mg} / \mathrm{dl}, p<0.005)$, higher serum triglycerides $(650 \mathrm{mg} / \mathrm{dl} v s .150 \mathrm{mg} / \mathrm{dl}, p<0.01)$, and lower high-density lipoprotein $(16 \%$ vs. $35 \%, p<0.05)$. On autopsy, discontinuous elastic fibers and intimal damage were seen in sections of the aortas from group B, but not from group A. After 5 days, group $\mathrm{C}$ had control levels of cholesterol (55 $\mathrm{mg} / \mathrm{dl})$ and triglycerides $(160 \mathrm{mg} / \mathrm{dl})$, and no significant difference from the control lipoprotein profile. Injections of cholesterol alone showed a slight induction of aortic lesions and blood chemistry changes. No alterations in these parameters were induced by ergocalciferol alone. The data indicate a prophylactic effect of vitamin $\mathrm{C}$ on the biochemical and histological changes rapidly induced by cholesterol and ergocalciferol.
\end{abstract}

Key Words atherosclerosis, aorta, cholesterol, vitamin C

Animal models using the rabbit have been developed to study human atherosclerosis. Both cholesterol-rich(1) and cholesterol-free (2) diets have been used to induce the morphological and biochemical alterations of this disease. Generally, these effects are seen after several months of feeding the special diet. To study the initial events of atherosclerosis a more rapid model is appropriate. Foam cell lesions have been induced in the rabbit aorta in 10 days via the injection of allylamine in egg yolk emulsion(3). Recently, a 5-day regimen of introducing cholesterol and ergocalciferol (vitamin $\mathrm{D}_{2}$ ) in olive oil via a stomach tube was used in rats. Aortic lesions (4) and biochemical changes $(5,6)$ consistent with atherosclerosis were observed. The first objective of the present study was to modify and 
validate the use of this rapid model in rabbits. The second was to examine the effects of vitamin $\mathrm{C}$ on the model.

\section{MATERIALS AND METHODS}

Male New Zealand white rabbits, weighing 1,800-2,300 g, were obtained from Mission Laboratory Supply, Rosemead, CA. The animals were maintained on a Purina laboratory chow diet, in quarters at $21 \pm 1^{\circ} \mathrm{C}$ and a photo-period of $14 \mathrm{hr}$ throughout the experiment. Chemicals and sources were: ascorbic acid, cholesterol, and ergocalciferol from Sigma Chemical Co., St. Louis, MO; dimethyl ethylene glycol (1,2-dimethoxy ethane) from J. T. Baker, Los Angeles, CA.

Five groups of rabbits (15 each in groups A, B and C; 10 each in group D and E) were injected intraperitoneally for 5 consecutive days, at $14: 00 \mathrm{hr}$, with one of the following: group A (control): $0.3 \mathrm{ml} / \mathrm{kg}$ dimethyl ethylene glycol (solvent); group B (induction): $40 \mathrm{mg} / \mathrm{kg}$ cholesterol and $3 \mathrm{mg} / \mathrm{kg}$ ergocalciferol(4) in 0.3 $\mathrm{ml} / \mathrm{kg}$ solvent; group C: same regimen as $B$ with the addition of $150 \mathrm{mg} / \mathrm{kg}$ ascorbic acid in $0.5 \mathrm{ml}$ water, injected separately; group D: $40 \mathrm{mg} / \mathrm{kg}$ cholesterol in $0.3 \mathrm{ml} / \mathrm{kg}$ solvent; group E: $3 \mathrm{mg} / \mathrm{kg}$ ergocalciferol in $0.3 \mathrm{ml} / \mathrm{kg}$ solvent. All solutions were made up immediately prior to use. Fasting $(10 \mathrm{hr})$ blood samples were taken at $08: 30 \mathrm{hr}$ on the 2 days prior to the start of the injections, and on the second, fourth and fifth days after the first injection day (day 0). Total serum cholesterol(7), triglycerides $(8,9)$ and ascorbic acid $(10)$ were determined spectrophotometrically. Lipoproteins were separated by agarose gel electrophoresis (11) and quantitated by densitometry (Corning).

On the fifth day after initial injection, the rabbits were killed by chloroform anaesthesia. A $1 \mathrm{~cm}$ region of the aortic arch was dissected, fixed in neutral formalin, embedded in paraffin and sectioned at $8 \mu \mathrm{m}$. Sections were stained with hematoxylin and eosin or specifically for elastic tissue (12). Four slides (two with each stain) per animal were selected at random and examined in a single-blind manner for the presence of aortic lesions.

Statistical analyses were carried using a Student's $t$-test for paired data.

\section{RESULTS}

During the experiment, no noticeable changes in overall food or water consumption were noted. Injections of solvent in amounts greater than $0.3 \mathrm{ml} / \mathrm{kg}$ were toxic, leading to a decrease in water consumption, lethargy, and, sometimes, death. On autopsy, the animals of group B had numerous 1-3 mm-wide fat bodies on the surfaces of the liver and lower digestive tract. Fewer such inclusions were noted in group D, and none in the other groups.

Figure 1 shows a lesion seen in the aorta of a group B rabbit, with a comparative section from a group A animal. Lesions were typically discontinuities of the elastic fibers and separations of the intima. Damaged intimal regions were 


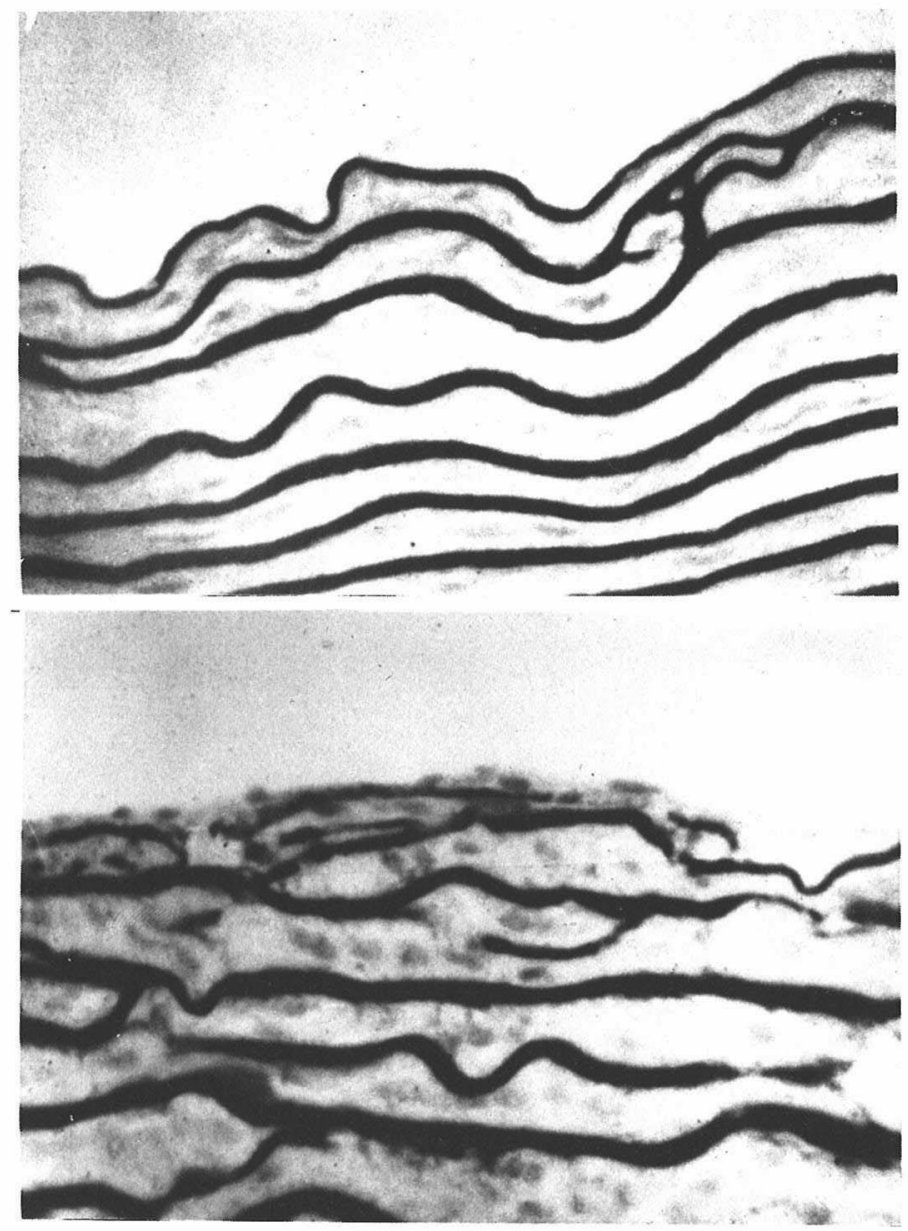

Fig. 1. Sections of intima of aorta, iron gallein stain, $\times 500$. Top: injected with solvent only (group A). Bottom: injected with cholesterol and ergocalciferol (group B).

sudanophilic, indicating a high lipid content. The histological observations are summarized in Table 1. Although injections with cholesterol alone (group D) resulted in an increased number of lesions over the control, the combination of cholesterol and ergocalciferol (group B) had the strongest adverse effect on aortic integrity. This effect was largely inhibited by the co-injection of vitamin C (group C).

Measurements of serum ascorbic acid levels were made for all animals on the second day before, and fifth day after, the first injection. Group means (Table 2) did not differ significantly $(p<0.05)$ from the control for any group or day except for group C on day 5 , with a level of $2.9 \mathrm{mg} / \mathrm{dl}(p<0.001)$.

Lipid-related blood chemistry data are shown in Tables 3-5. In Table 3, Vol. 28, No. 2, 1982 
Table 1. Histological observations of aortas.

\begin{tabular}{|c|c|c|c|c|c|}
\hline \multirow{2}{*}{ Group } & \multirow{2}{*}{$n$} & \multicolumn{2}{|c|}{ Number of slides } & \multicolumn{2}{|c|}{ Number of animals } \\
\hline & & Lesion & No lesion & Lesion & No lesion \\
\hline A: Solvent only & 15 & 2 & 58 & 1 & 14 \\
\hline $\begin{array}{r}\text { B: Cholesterol+ } \\
\text { ergocalciferol }\end{array}$ & 15 & 46 & 14 & 11 & 4 \\
\hline $\begin{aligned} \text { C: } & \text { Cholesterol+ } \\
& \text { ergocalciferol + } \\
& \text { vitamin C }\end{aligned}$ & 15 & 13 & 47 & 4 & 11 \\
\hline D: Cholesterol & 10 & 22 & 18 & 5 & 5 \\
\hline E: Ergocalciferol & 10 & 0 & 40 & 0 & 10 \\
\hline
\end{tabular}

Table 2. Serum ascorbic acid. ${ }^{\mathrm{a}}$

\begin{tabular}{ccc}
\hline & \multicolumn{2}{c}{ Serum ascorbic acid } \\
\cline { 2 - 3 } Group & Day -2 & Day +5 \\
\hline $\begin{array}{l}\text { A: Solvent only } \\
\text { B: Cholesterol+ } \\
\quad \text { ergocalciferol }\end{array}$ & $1.4 \pm 0.2$ & $1.3 \pm 0.3$ \\
$\begin{array}{c}\text { C: Cholesterol + } \\
\text { ergocalciferol }\end{array}$ & $1.6 \pm 0.5$ & $1.5 \pm 0.4$ \\
$\quad$ vitamin C & $1.4 \pm 0.2$ & $2.9 \pm 0.3^{*}$ \\
D: Cholesterol & $1.3 \pm 0.3$ & $1.4 \pm 0.4$ \\
E: Ergocalciferol & $1.5 \pm 0.4$ & $1.5 \pm 0.2$ \\
\hline
\end{tabular}

${ }^{a}$ Values are expressed as mean $\mathrm{mg} / \mathrm{dl} \pm \mathrm{SD}$. Groups and numbers of animals are identical to Table 1. Injections were begun on day $0 .{ }^{*} p<0.001$ compared to all other groups for that day.

significant differences in total serum cholesterol between group B and the other groups occurred at days $4(p<0.01)$ and $5(p<0.005)$. Group D also showed a significant increase $(p<0.01)$ on day 5. In Table 4 , significant $(p<0.01)$ differences in serum triglycerides between group B and the other groups occurred at days 2,4 and 5. In Table 5, lipoprotein data are expressed as percent high-density lipoprotein (HDL) since this component is believed to be antiatherosclerotic (13). The variation in the other components of the electrophoretic profile-chylomicrons, very-lowdensity lipoprotein, and low density lipoprotein - was almost entirely in the latter. Significant $(p<0.05)$ differences in $\%$ HDL between group B and the other groups occurred at days 4 and 5 . 
Table 3. Serum total cholesterol. ${ }^{\mathrm{a}}$

\begin{tabular}{lccccc}
\hline & \multicolumn{5}{c}{ Serum total cholesterol } \\
\cline { 2 - 6 } & Day -2 & Day -1 & Day +2 & Day +4 & Day +5 \\
\hline $\begin{array}{l}\text { A: Solvent only } \\
\text { B: Cholesterol + } \\
\quad \text { ergocalciferol }\end{array}$ & $79 \pm 19$ & $66 \pm 24$ & $69 \pm 21$ & $76 \pm 29$ & $62 \pm 32$ \\
$\begin{array}{l}\text { C: Cholesterol + } \\
\text { ergocalciferol+ }\end{array}$ & $64 \pm 21$ & $55 \pm 26$ & $111 \pm 39$ & $135 \pm 19^{*}$ & $150 \pm 17^{*}$ \\
$\quad$ vitamin C & $60 \pm 18$ & $70 \pm 19$ & $64 \pm 29$ & $61 \pm 28$ & $57 \pm 21$ \\
D: Cholesterol & $72 \pm 28$ & $69 \pm 14$ & $74 \pm 31$ & $89 \pm 31$ & $109 \pm 21^{*}$ \\
E: Ergocalciferol & $71 \pm 25$ & $74 \pm 20$ & $69 \pm 28$ & $75 \pm 22$ & $76 \pm 30$ \\
\hline
\end{tabular}

${ }^{a}$ Values are expressed as mean $\mathrm{mg} / \mathrm{dl} \pm \mathrm{SD}$. Groups and numbers of animals are identical to Table 1 . Injections were begun on day $0 .{ }^{*} p<0.01$ compared to all other groups for that day.

Table 4. Serum triglycerides. ${ }^{\mathrm{a}}$

\begin{tabular}{|c|c|c|c|c|c|}
\hline \multirow{2}{*}{ Group } & \multicolumn{5}{|c|}{ Serum triglycerides } \\
\hline & Day -2 & Day -1 & Day +2 & Day +4 & Day +5 \\
\hline A: Solvent only & $162 \pm 91$ & $164 \pm 69$ & $137 \pm 77$ & $203 \pm 48$ & $165 \pm 99$ \\
\hline $\begin{array}{r}\text { B: Cholesterol+ } \\
\text { ergocalciferol }\end{array}$ & $176 \pm 58$ & $173 \pm 88$ & $371 \pm 98^{*}$ & $550 \pm 121^{*}$ & $652 \pm 155^{*}$ \\
\hline $\begin{aligned} \text { C: Cholesterol+ } \\
\quad \text { ergocalciferol+ } \\
\quad \text { vitamin C }\end{aligned}$ & $192 \pm 66$ & $190 \pm 101$ & $178 \pm 86$ & $175 \pm 80$ & $170 \pm 104$ \\
\hline D: Cholesterol & $184 \pm 38$ & $171 \pm 90$ & $195 \pm 90$ & $221 \pm 93$ & $258 \pm 134$ \\
\hline E: Ergocalciferol & $173 \pm 61$ & $188 \pm 71$ & $165 \pm 89$ & $197 \pm 81$ & $195 \pm 88$ \\
\hline
\end{tabular}

${ }^{\text {a }}$ Values are expressed as mean $\mathrm{mg} / \mathrm{dl} \pm \mathrm{SD}$. Groups and numbers of animals are identical to Table 1 . Injections were begun on day $0 .{ }^{*} p<0.01$ compared to all other groups for that day.

\section{DISCUSSION}

The first objective of this study was to develop a model for the rapid induction of aortic lesions in rabbits. A rat model was used for daily introduction of an emulsion of cholesterol and ergocalciferol in olive oil(4) via gastric tube for five days. This was modified in the present study by the use of a solvent, dimethyl ethylene glycol, and a regimen of injections. Control experiments (group A) showed that the solvent had no discernible effects on the integrity of the aorta (Table 1) nor on blood chemistry measurements (Tables 3-5). Cholesterol alone (group D) but not 
Table 5. Serum high-density lipoproteins. ${ }^{a}$

\begin{tabular}{lccccc}
\hline \multirow{2}{*}{ Group } & \multicolumn{5}{c}{ Serum \% HDL } \\
\cline { 2 - 6 } & Day -2 & Day -1 & Day +2 & Day +4 & Day +5 \\
\hline $\begin{array}{l}\text { A: Solvent only } \\
\text { B: Cholesterol+ } \\
\quad \text { ergocalciferol }\end{array}$ & $36 \pm 23$ & $39 \pm 26$ & $41 \pm 20$ & $33 \pm 21$ & $35 \pm 17$ \\
$\begin{array}{l}\text { C: Cholesterol+ } \\
\text { ergocalciferol+ } \\
\text { vitamin C }\end{array}$ & $40 \pm 26$ & $35 \pm 16$ & $14 \pm 12$ & $16 \pm 7^{*}$ & $15 \pm 7^{*}$ \\
$\begin{array}{l}\text { D: Cholesterol } \\
\text { E: Ergocalciferol }\end{array}$ & $37 \pm 22$ & $34 \pm 18$ & $30 \pm 16$ & $29 \pm 19$ & $29 \pm 19$ \\
\hline
\end{tabular}

${ }^{a}$ Values are expressed as mean HDL as percentage of total lipoproteins \pm SD. Groups and numbers of animals are indentical to Table 1 . Injections were begun on day 0 . $* p<0.05$ compared to all other groups for that day.

ergocalciferol alone (group E) led to some histological and biochemical changes. This is in contrast to the rat model, where ergocalciferol, but not cholesterol, had pronounced effects(5). Vitamin D was previously shown to be atherogenic in swine (14).

Pretreatment levels of serum cholesterol, triglycerides and high-density lipoproteins were similar to those previously reported for this strain of rabbit (15). However, these levels were considerably altered over the 5-day injection period with a combination of cholesterol and ergocalciferol. While the significant hypercholesterolemia (Table 3) was not as great as that observed after several months on a high-cholesterol diet, the increased triglycerides (Table 4) and decreased \% HDL (Table 5) were of magnitudes consistent with the development of atherosclerosis (16). Increased \% LDL, which occurs concomitant with decreased \% HDL in rabbits (17) may be atherogenic by invasion of the endothelial wall(18). Epidemiological studies have implicated the involvement of increased $\%$ LDL with human atherosclerosis (19). The lesions observed in the aorta (Fig. 1) were similar to those previously reported in a model for the rapid induction of atherosclerosis by allylamine injections (3).

The second objective of this study was to examine the effects of vitamin $\mathrm{C}$ on the rapid model. This vitamin has been suggested as a possible therapeutic agent for atherosclerosis (for reviews see 20,21). Vitamin $\mathrm{C}$ has its greatest antiatherosclerotic effects in hypercholesterolemic animals and patients $(22,23)$ and therefore might be expected to alleviate the hypercholesterolemia (Table 3) seen in this model. Such an effect was indeed observed. Co-injection of vitamin C (group C) doubled the serum level of this vitamin (Table 2) and largely prevented the histological (Table 1) and biochemical (Tables 3-5) changes induced by cholesterol and ergocalciferol. The rabbit synthesizes $140 \mathrm{mg} / \mathrm{kg}$ /day of ascorbic acid and thus the injection of an 
additional $140 \mathrm{mg} / \mathrm{kg} /$ day would be expected to double the serum level of this vitamin; such was the case. Possible mechanisms for the prophylactic effects of vitamin $\mathrm{C}$ on the rapid model include increased HDL (Table 5, Ref. 24, 25), decreased blood clotting and platelet aggregation (26), decreased serum triglycerides (Table 4, Ref. 27), alterations in lipoprotein metabolism within the aorta (28) and lowered serum cholesterol due to increased sulfation (29-32) or conversion to bile acids (33). The rapid model described here may be useful in distinguishing among these alternative hypotheses.

We thank the Pathology Medical Group, Pomona CA, for assistance with the blood chemistry measurements, and Drs. D. Kritchevsky, D. Steinberg and D. Kramsch for discussions.

\section{REFERENCES}

1) Anitschkow, N. (1933): Experimental atherosclerosis in animals, in Arteriosclerosis: A Survey of the Problem, ed. by Cowdry, E. V., MacMillan, New York, p. 271-291.

2) Kritchevsky, D. (1964): Experimental atherosclerosis in rabbits fed cholesterol-free diets. J. Atheroscler. Res., 4, 103-105.

3) Giordano, A. R., Sparagen, S. C., and Hamel, H. (1970): A model for the rapid production of atheromatous lesions in rabbits. Lab. Invest., 22, 94-99.

4) Altman, R. F. A. (1973): A simple method for the production of atherosclerosis in rats. Experientia, 29, 256.

5) Testa, R., Canestrini, C., and Oldani, C. (1975): Experimental atherosclerosis in the rat: biochemical evaluation. J. Pharm. Pharmac., 27, 699-700

6) Yousufzai, S., and Siddiqui, M. (1976): 3-Hydroxy-3-methylglutaric acid and experimental atherosclerosis in rats. Experientia, 32, 1033-1035.

7) Kin, E., and Goldberg, M. (1969): Serum cholesterol assay using a stable LiebermannBurchard reagent. Clin. Chem., 15, 1171-1175.

8) Van Handel, E., and Zilversmit, D. B. (1957): Micromethod for the direct determination of serum triglycerides. J. Lab. Clin. Med., 50, 152-157.

9) Van Handel, E. (1961): Suggested modifications of the micro determination of triglycerides. Clin. Chem., 7, 249-251.

10) Roe, J. H., and Keuther, G. (1943): The determination of ascorbic acid in whole blood and urine through the 2,4-dinitrophenylhydrazine derivative of dehydroascorbic acid. J. Biol. Chem., 147, 399-407.

11) Noble, R. P. (1958): Electrophoretic separation of plasma lipoproteins in agarose gel. $J$. Lipid Res., 9, 693-698.

12) Churukian, C. J., and Schenk, E. A. (1976): Iron gallein elastic method-a substitute for Verhoeff's elastic tissue strain. Stain Technol., 51, 213-217.

13) Schwartz, C., Halloran, G., and Vlahcevic, Z. (1978): Preferential utilization of free cholesterol from high-density lipoproteins for biliary cholesterol secretion in man. Science, 200, 62-64.

14) Taura, S., Taura, M., Kamio, A., and Kummerow, F. A. (1979): Vitamin D-induced coronary atherosclerosis in normolipemic swine: comparison with human disease. Tohoku J. Exp. Med., 129, 9-16.

15) Altman, P. C., and Ditmer, D. S. (1974): Biology Data Book (Ed. 2), Fed. Am. Soc. 
Exp. Biol., Bethesda, MD, p. 1817.

16) Hayashi, E., Yamada, J. Kunitomo, M. Terada, M., and Sato, M. (1978): Fundamental studies on physiological and pharmacological actions of L-ascorbate-2-sulfate. Jpn. J. Pharmacol., 28, 61-72.

17) Shore, B., and Shore, V. (1976): Rabbits as a model for the study of hyperlipoproteinemia and atherosclerosis. Adv. Exp. Med. Biol., 67, 123-130.

18) Walton, K. (1975): Pathogenic mechanisms in atherosclerosis. Am. J. Cardiol., 35, 542550.

19) Kannel, W., Castelli, W., and Gordon, T. (1979): Cholesterol in the prediction of atherosclerotic disease. Ann. Int. Med., 90, 85-90.

20) Krumdieck, C., and Butterworth, C. E. (1974): Ascorbate-cholesterol-lecithin interactions: factors of potential importance in the pathogenesis of atherosclerosis. Am. J. Clin. Nutr., 27, 866-876.

21) Turley, S. D., West, C. D., and Horton, B. J. (1976): The role of ascorbic acid in the regulation of cholesterol metabolism and in the pathogenesis of atherosclerosis. Atherosclerosis, 24, 1-18.

22) Kent, S. (1978): Vitamin C therapy, colds, cancer, and cardiovascular disease. Geriatrics, 33, 91-94.

23) Ginter, E. (1979): Pretreatment serum cholesterol and response to ascorbic acid. Lancet, 2, 958.

24) Novitskii, A. (1969): Influence of vitamin $C$ on cholesterol metabolism in the liver in experimental atherosclerosis. Cor et Vasa, 11, 302-310.

25) Bates, C. J., Mandal, A. R., and Cole, T. J. (1977): HDL-cholesterol and vitamin C status. Lancet, $2,611$.

26) Bordia, A. K. (1980): The effect of vitamin C on blood lipids, fibrinolytic activity, and platelet adhesiveness in patients with coronary artery disease. Atherosclerosis, 35, 181189.

27) Sokoloff, B., Hori, M., Saehlof, C., McConnell, B., and Imai, T. (1976): Effects of ascorbic acid on certain blood fat metabolism factors in animals and man. J. Nutr., 91, $107-115$.

28) Coetzee, G., Stein, O., and Stein, Y. (1979): Modulation by sodium ascorbate of the effect of chloroquine on low density lipoprotein retention and degradation in cultured skin fibroblasts. Atherosclerosis, 32, 277-287.

29) Baker, E. M., Hammer, D. C., March, S. C., Tolbert, B. M., and Canham, J. C. (1971): Ascorbate sulfate: a urinary metabolite of ascorbic acid in man. Science, 173, 826-827.

30) Verlangieri, A. J., and Mumma, R. O. (1973): In vivo sulfation of cholesterol by ascorbic acid-2-sulfate. Atherosclerosis, 17, 34-48.

31) Verlangieri, A. J., Hollis, T. M., and Mumma, R. O. (1977): Effects of ascorbic acid and its 2-sulfate on rabbit aortic intimal thickening. Blood Vessels, 14, 157-174.

32) Verlangieri, A. J., and Stevens, J. W. (1979): L-Ascorbic acid: effects on aortic glycosaminoglycan. ${ }^{35} \mathrm{~S}$-incorporation in rabbit induced atherogenesis. Blood Vessels, 16, 177-185.

33) Ginter, E. (1978): Marginal vitamin C deficiency, lipid metabolism, and atherogenesis. Adv. Lipid Res., 16, 167-220. 